\title{
Glasgow Aneursym Score: A Predictor of Long-Term Mortality Following Endovascular Repair of Abdominal Aortic Aneurysm?
}

\author{
Anıl Özen ( $\sim$ anil_ozen@hotmail.com ) \\ Ankara State Hospital \\ Metin YIImaz \\ VM Medicalpark Hospital \\ Görkem Yiğit \\ Yozgat State Hospital \\ İsa Civelek \\ Ankara State Hospital \\ Mehmet Ali Türkçü \\ Ankara State Hospital \\ Ferit Çetinkaya \\ Ankara State Hospital \\ Ertekin Utku Ünal \\ Hitit University Faculty of Medicine \\ Hakkı Zafer İşcan \\ Ankara State Hospital
}

\section{Research Article}

Keywords: Endovascular, Aortic aneurysm, Risk assessment, Analysis, Survival, Mortality

Posted Date: August 13th, 2021

DOI: https://doi.org/10.21203/rs.3.rs-763491/v1

License: (c) (1) This work is licensed under a Creative Commons Attribution 4.0 International License. Read Full License

Version of Record: A version of this preprint was published at BMC Cardiovascular Disorders on November 19th, 2021. See the published version at https://doi.org/10.1186/s12872-021-02366-y. 


\section{Abstract \\ Background}

To evaluate the value of Glasgow Aneurysm Score (GAS) in predicting long-term mortality and survival in patients who have undergone endovascular aortic aneurysm repair (EVAR) for abdominal aortic aneurysm (AAA).

\section{Methods}

A retrospective single-center study of 257 patients with non-ruptured AAA undergoing EVAR between January 2013 and 2021. GAS scores were compared between the survivors and the long term mortality groups. Receiver operating characteristic curve (ROC) analysis was used to determine the optimum cutoff values of GAS values to determine the effect on late-mortality.

\section{Results}

257 patients with a mean age of $69.75 \pm 7.75(46-92)$ underwent EVAR due to AAA. Forty-nine mortalities were observed, 4 (1.5\%) were in-hospital mortalities. Fourty-five $(17.8 \%)$ of the mortalities occured during the long-term follow-up. The average follow up period was $18.98 \pm 22.84$ months $(0-88)$. GAS values were higher in the long-term mortality group compared to the survivors group (81.02 \pm 10.33 vs $73.73 \pm$ $10.46 ; p<0.001)$. The area under the ROC curve for GAS was 0.682 and for a $56 \%$ sensitivity rate, the cutoff value for GAS was 77.5 with a specificity of $64 \%(p<0.001)$. The number of patients with GAS values $<77.5$ was 155 , whilst 98 had GAS values $>77.5$. The mortality rates in patients with GAS $<77.5$ and GAS $>77.5$ were: $12.8 \%(n=20)$ and $24.8 \%(n=25)$, respectively $(p=0.014)$. Every 1 point increase in GAS score resulted in a 1.06 fold increase in risk of late mortality (OR: 1.06, 95\% Cl, 1.03-1.09; p < 0.001). Moreover, every 10 point increase in GAS score resulted in almost a 2 fold increase in risk of long-term mortality (OR: $1.8,95 \% \mathrm{Cl}, 1.3-2.5 ; \mathrm{p}<0.001)$. The mean survival rate of the patients during the follow up period was $90.6 \%$ for the 1 st year, $82.6 \%$ for the 3 rd year and $70.0 \%$ for the 5 th year. Five year survival rates in patients with GAS $<77.5$ and $>77.5$ were $75.7 \%$ and $61.7 \%$, respectively $(p=0.013)$.

\section{Conclusion}

Every 10 point increase in GAS score resulted in almost a 2 fold increase in risk of long-term mortality. Moreover, the mortality rates in patients above the GAS cut off value almost doubled compared to those below. Five year survival rates were $14 \%$ higher in those with GAS below the cut off value when compared to those above.

\section{Introduction}


Endovascular aortic aneurysm repair (EVAR) is a contemporary, accepted treatment modality used in abdominal aortic aneurysm (AAA) repair due to its less invasive nature compared to open surgery [1]. It possesses early mortality advantages and results in shorter duration of hospital stay. Nevertheless, reinterventions are more frequent following EVAR and lifelong follow-up is necessary [2].

Various scoring systems such as the Glasgow Aneurysm Score (GAS), Hardman Index (HI), Leiden score and Vanzetto score have been used to predict the outcomes after open surgical repair (OSR) of the AAA [3]. GAS is a practical and objective scoring system, devised in the 1980-1990s to predict mortality following elective open AAA repair [4]. Later on, it was also applied to patients undergoing $\operatorname{EVAR}[5,6]$. Even though it is a scoring sytem whose validity and reliability has previously been shown, studies on post-EVAR long-term follow-up outcomes predicted using the GAS, are scarce $[5,6]$.

This study aims to evaluate the value of GAS in predicting long-term mortality and survival in patients who have undergone EVAR for AAA. In addition, the aim was to define a cut-off value for GAS and investigate the patient outcomes according to this value.

\section{Material And Methods}

\section{Study design}

This study complied with the Declaration of Helsinki, and ethical approval was granted by the local institutional review board. Informed consent was obtained from all study participants.

A single centre, retrospective study of 257 patients diagnosed with non-ruptured AAA, who had undergone EVAR in our hospital between January 2013 and January 2021. Patients with a mean age of $69.75 \pm 7.75$ (46-92) who underwent EVAR of infrarenal AAAs were included in the study. Patients with AAAs with a diameter $\geq 5.5 \mathrm{~cm}$, saccular morphology regardless of the diameter, or rapid aneurysm growth $>5 \mathrm{~mm}$ in 6 months were eligible for EVAR. Exclusion criteria included: emergency admissions (mainly ruptured aneurysms), presence of thoracoabdominal aneurysms, isolated iliac aneurysms, those who underwent open aneurysm repair procedures and hybrid revascularization. Technical details of stent deployment have been described previously [7]. The patients were followed up on an outpatient basis 1, 6, 12, 18 and 24 months post-EVAR, and annually thereafter. Those who did not come to the outpatient clinic for follow up were contacted via telephone. According to the patient follow up, study participants were divided into two groups; the survivors and the long-term mortality cases ( $\geq 1$ month post EVAR).

Patients' demographic data included: age and sex and clinical features such as ejection fraction (EF) and other concomitant disorders such as previous cardiovascular, respiratory, renal, neurological disorders and past medical history of cancer. The clinical features of each patient was used to calculate the GAS score: the sum of age, +7 points for myocardial disease, +10 points for cerebrovascular disease, and +14 points for renal disease. Myocardial disease included previously documented myocardial infarction or ongoing angina pectoris or both. Cerebrovascular disease included stroke and transient ischemic attack. 
Renal dysfunction was defined as a serum creatine level >150 mmol/L or a urea > $20 \mathrm{mmol} / \mathrm{L}$ or a history of acute or chronic renal failure or both [4].

Receiver operating characteristic curve (ROC) analysis was used to determine the optimum cut-off values of GAS values to determine the effect on late-mortality. Pre-procedural aneurysm diameter, based on computerised tomography (CT) evaluation, and GAS scores were compared between the survivors and the long term mortality group. The groups were also compared with regards to operative and postoperative data (operation time, fluoroscopy time, volume of contrast medium used, length of intensive care unit (ICU) and hospital stay. Finally, the independent risk predictors for late-mortality were analysed. This was followed by survival analysis in the $1 \mathrm{st}$, 3rd and 5th years post-EVAR.

\section{Statistical analysis}

All statistical analyses were performed using the SPSS statistical software (SPSS for Windows 15.0, Inc., Chicago, IL, USA). Continuous variables were tested for normal distribution using the KolmogorovSmirnov test. Normally distributed continuous variables were expressed as 'mean values \pm standard deviation (SD)' or median values with the interquartile range if not normally distributed. Categorical variables were expressed as numbers and percentages. Demographic characteristics, perioperative variables and calculated values were compared using "independent samples $t$-test" or "Mann-Whitney- $U$ test" for continuous variables and "chi-square test" or "Fisher's exact test" for categorical variables. Correlations were assessed using Spearman's correlation test. Receiver operating characteristic curve analysis was used to determine the optimum cut-off values of GAS values to determine the effect on latemortality. The odds ratios and 95\% confidence intervals were estimated with different logistic regression models that were created to determine independent predictors of late mortality. All the variables that were found to be different at univariate analysis, were included in Model 1. GAS values were assessed in Model 2 and the parameters that were included in GAS value calculation were extracted from Model 2. Kaplan-Meier analysis was conducted to demonstrate the survival. A p value $<0.05$ was considered statistically significant.

\section{Results}

\section{Patients demographics}

Two hundred and fifty seven patients underwent EVAR due to AAA. A total of 49 mortalities were observed, 4 (1.5\%) were in-hospital mortalities and were excluded from the study analysis. Fourty-five $(17.8 \%)$ of the mortalities occured during the long-term follow-up. The average follow up period was $18.98 \pm 22.84$ months $(0-88)$. Two hundred and eight patients $(82.2 \%)$ were alive for the entirerity of the follow-up period.

Demographic characteristics of the patients are given in Table 1. There were no female patients in the long-term mortality group $(0 \%, p<0.029)$. The American Association of Anesthesiologists (ASA) Physical Status Classification System 1 and 2 were significantly higher in the survivors group and ASA 3 and 4 
were significantly higher in the long-term mortality group $(p<0.001)$. Moreover, incidence of COPD $(p=$ $0.011), \operatorname{CAD}(p<0.020), \operatorname{CHF}(p<0.001)$ and history of malignancy $(p=0.005)$ were all higher in the longterm mortality group. 
Table 1

Demographic characteristics of the patients

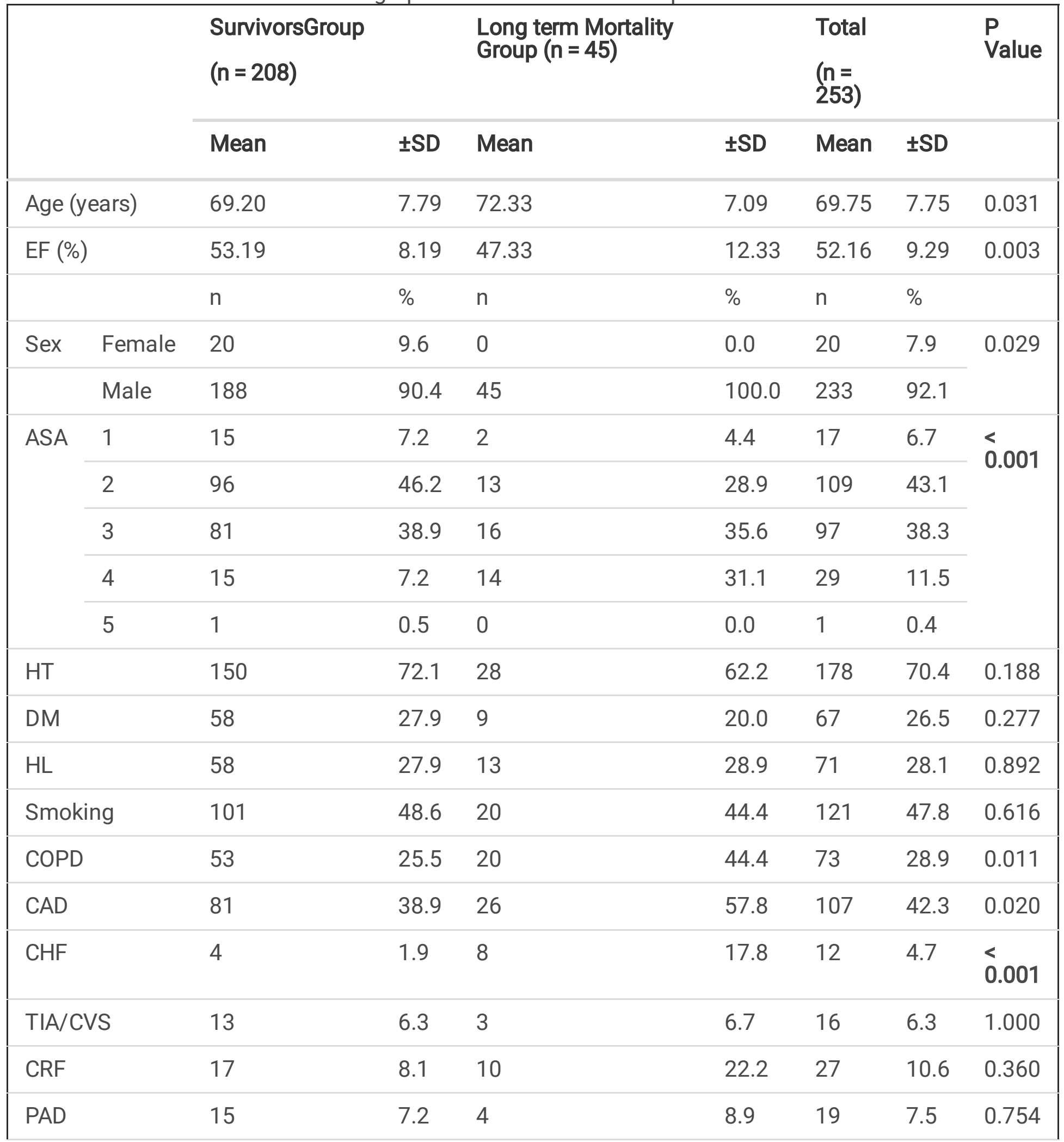

SD: Standard deviation; EF: Ejection fraction; HT: Hypertension; HL:Hyperlipidemia; DM: Diabetes mellitus; COPD: Chronic obstructive pulmonary disease; CAD: Coronary artery disease; CHF: Congestive heart failure; TIA/CVS: Transient ischemic attack/cerebrovascular stroke; CRF: Chronic renal failure; PAD: Peripheral artery disease; ASA: American Society of Anesthesiologists classification. 


\begin{tabular}{|c|c|c|c|c|c|c|c|}
\hline & $\begin{array}{l}\text { SurvivorsGroup } \\
(\mathrm{n}=208)\end{array}$ & & $\begin{array}{l}\text { Long term Mortality } \\
\text { Group }(n=45)\end{array}$ & & $\begin{array}{l}\text { Total } \\
(\mathrm{n}= \\
253)\end{array}$ & & $\begin{array}{l}\mathrm{P} \\
\text { Value }\end{array}$ \\
\hline & Mean & $\pm S D$ & Mean & $\pm S D$ & Mean & $\pm S D$ & \\
\hline Cancer & 7 & 3.4 & 7 & 15.6 & 14 & 5.5 & 0.005 \\
\hline Symptomatic & 61 & 29.3 & 17 & 37.8 & 78 & 30.8 & 0.266 \\
\hline \multicolumn{8}{|c|}{$\begin{array}{l}\text { SD: Standard deviation; EF: Ejection fraction; HT: Hypertension; HL:Hyperlipidemia; DM: Diabetes } \\
\text { mellitus; COPD: Chronic obstructive pulmonary disease; CAD: Coronary artery disease; CHF: } \\
\text { Congestive heart failure; TIA/CVS: Transient ischemic attack/cerebrovascular stroke; CRF: Chronic } \\
\text { renal failure; PAD: Peripheral artery disease; ASA: American Society of Anesthesiologists } \\
\text { classification. }\end{array}$} \\
\hline
\end{tabular}

\section{Comparison of GAS, aortic diameter and intra and postoperative data}

Comparison of GAS, aortic diameter and intra and postoperative data between the groups (survivors vs long-term mortality group) are summarized in Table 2. GAS values were significantly higher in the longterm mortality group compared to the survivors group ( $81.02 \pm 10.33$ vs $73.73 \pm 10.46 ; p<0.001)$. There was no correlation between the GAS values and in-hospital mortality $(p=0.091)$. There was no significant difference in aortic diameters between the two groups $(p=0.134)$. ICU and hospital stay were longer in the long-term mortality group ( $p<0.001$ and $p=0.002$, respectively). In addition, there was a weak correlation between GAS and ASA, and duration of ICU stay ( $r=0.157 ; r=0.593$, respectively). A strong correlation was found between the GAS and the duration of hospital stay $(r=0.593)$. 
Table 2

Comparison of GAS, aortic diameter and postoperative data between the groups (survivors vs latemortality group)

\begin{tabular}{|c|c|c|c|c|c|c|c|}
\hline & \multicolumn{2}{|c|}{$\begin{array}{l}\text { Survivors }(n= \\
208)\end{array}$} & \multicolumn{2}{|c|}{$\begin{array}{l}\text { Late-Mortality Group } \\
(n=45)\end{array}$} & \multicolumn{2}{|c|}{$\begin{array}{l}\text { Total }(n= \\
253)\end{array}$} & \multirow[t]{2}{*}{$\begin{array}{l}P \\
\text { values }\end{array}$} \\
\hline & Mean & $\pm S D$ & Mean & $\pm S D$ & Mean & $\pm S D$ & \\
\hline GAS & 73.73 & 10.46 & 81.02 & 10.33 & 75.05 & 10.79 & $<0.001$ \\
\hline $\begin{array}{l}\text { Aneurysm } \\
\text { diameter/mm }\end{array}$ & 63.32 & 12.71 & 66.33 & 13.69 & 63.92 & 12.94 & 0.134 \\
\hline Operation time/min & 135.68 & 49.37 & 135.00 & 36.91 & 135.56 & 47.22 & 0.767 \\
\hline Fluoroscopy time/min & 17.08 & 10.87 & 18.85 & 10.66 & 17.43 & 10.82 & 0.013 \\
\hline $\begin{array}{l}\text { Amount of contrast } \\
\text { medium /cc }\end{array}$ & 63.59 & 22.45 & 67.15 & 23.18 & 64.28 & 22.58 & 0.238 \\
\hline ICU stay/hour & 6.26 & 7.24 & 17.27 & 38.72 & 8.25 & 18.11 & $<0.001$ \\
\hline Hospital stay/day & 2.79 & 2.94 & 4.00 & 3.56 & 3.00 & 3.08 & 0.002 \\
\hline
\end{tabular}

\section{ROC analysis and Logistic Regression}

The area under the ROC curve for GAS was 0.682 and for a $56 \%$ sensitivity rate, the cut-off value for GAS was 77.5 with a specificity of $64 \%(p<0.001)$. The findings of this analysis are given in Fig. 1.

Multivariate logistic regression analysis of the survivors and the long-term mortality groups in terms of GAS and GAS parameters, revealed that GAS and presence of malignancy were independent risk predictors for long-term mortality. The Multiple Logistic Regression model that included the GAS as a variable, revealed that a past medical history of malignancy resulted in a 5 fold increase in risk for longterm mortality (OR: $5.22,95 \% \mathrm{Cl}, 1.64-16.64 ; \mathrm{p}=0.005)$. The same model also displayed that, every 1 point increase in GAS score resulted in a 1.06 fold increase in risk of late mortality (OR: $1.06,95 \% \mathrm{Cl}$, 1.03-1.09; $p$ 0.001). Moreover, every 10 point increase in GAS score resulted in almost a 2 fold increase in risk of long-term mortality (OR: $1.8,95 \% \mathrm{Cl}, 1.3-2.5 ; p<0.001)$. The number of patients with GAS values $<77.5$ was 155 , whilst it was 98 with GAS values $>77.5$. The mortality rates in patients with GAS < 77.5 and GAS > 77.5 were: $12.8 \%$ (20 patients) and 24.8\% (25 patients), respectively $(p=0.014)$. However, the mean hospital stay was not statistically significanyt in patients with GAS $<77.5$ and $>77.5(2.83 \pm$ 2.688 vs $3.13 \pm 3.526)(p: 0.587)$. No correlation was found between GAS and endoleak. A low-grade positive correlation was found between GAS and ASA $(r=0.384, p<0.001)$. The findings of this analysis are summarized in Table 3. Causes of death during follow-up were; cardiovascular in 23, aneursysm related in 12, malignancy in 4, renal failure in 2, neurological in 2 and peripheral vascular in 2 patients. 
Table 3

Multivariate logistic regression analysis for assesment of independent risk predictors for late-mortality

\begin{tabular}{|c|c|c|c|c|c|c|}
\hline \multicolumn{3}{|c|}{ Univariate } & \multicolumn{2}{|c|}{ Multivariate model 1} & \multicolumn{2}{|c|}{ Multivariate model 2} \\
\hline Age & $1.06(1.01-1.11)$ & 0.010 & $\begin{array}{l}1.04(0.99- \\
1.09)\end{array}$ & 0.110 & & \\
\hline Sex & - & 0.998 & & & & \\
\hline ASA & - & 1.000 & & & & \\
\hline COPD & $2.34(1.20-4.55)$ & 0.012 & $\begin{array}{l}1.78(0.86- \\
3.72)\end{array}$ & 0.122 & $1.98(0.98-4.00)$ & 0.057 \\
\hline CAD & $2.15(1.12-4.13)$ & 0.022 & $\begin{array}{l}1.55(0.73- \\
3.29)\end{array}$ & 0.259 & & \\
\hline $\mathrm{CHF}$ & $\begin{array}{l}11.03(3.16- \\
38.50)\end{array}$ & $<.001$ & $\begin{array}{l}2.80(0.55- \\
14.36)\end{array}$ & 0.218 & & \\
\hline TIA/CVS & $0.93(0.26-3.42)$ & 0.917 & & & & \\
\hline Cancer & $\begin{array}{l}5.29(1.76- \\
15.95)\end{array}$ & 0.003 & $\begin{array}{l}4.48(1.29- \\
15.50)\end{array}$ & 0.018 & $\begin{array}{l}5.22(1.64- \\
16.64)\end{array}$ & 0.005 \\
\hline CRF & $3.43(1.44-8.17)$ & 0.005 & $\begin{array}{l}1.78(0.62- \\
5.12)\end{array}$ & 0.284 & & \\
\hline GAS & $1.07(1.03-1.10)$ & $\begin{array}{l}< \\
0.001\end{array}$ & & & $\begin{array}{l}1.06(1.03- \\
1.09)\end{array}$ & $<0.001$ \\
\hline EF & $0.94(0.91-0.97)$ & $<0.001$ & $\begin{array}{l}0.98(0.93- \\
1.03)\end{array}$ & 0.424 & & \\
\hline Fluoroscopy & $1.01(0.99-1.04)$ & 0.350 & & & & \\
\hline $\begin{array}{l}\text { EF: Ejection } \\
\text { CHF: Conges } \\
\text { Peripheral ar } \\
\text { renal failure. }\end{array}$ & $\begin{array}{l}\text { tion; COPD: Chror } \\
\text { e heart failure; TIA } \\
\text { / disease; } A S A \text { : An }\end{array}$ & $\begin{array}{l}\text { obstru } \\
\text { VS: Tra } \\
\text { ican Sc }\end{array}$ & $\begin{array}{l}\text { ve pulmonary } \\
\text { ient ischemic } \\
\text { ety of Anesth }\end{array}$ & $\begin{array}{l}\text { e; } C A D \\
\text { /cereb } \\
\text { yists cla }\end{array}$ & $\begin{array}{l}\text { Toronary artery di } \\
\text { vascular stroke; } P \\
\text { sification; } C R F: \text { Ch }\end{array}$ & $\begin{array}{l}\text { ase; } \\
\text { onic }\end{array}$ \\
\hline
\end{tabular}

\section{Survival analysis}

The mean survival rate of the patients during the follow up period was $90.6 \%$ for the 1 st year, $82.6 \%$ for the 3rd year and $70.0 \%$ for the 5th year (Fig. 2). Five year survival rates in patients with GAS $<77.5$ and > 77.5 were: $75.7 \%$ and $61.7 \%$, respectively $(p=0.013)$ (Fig. 3$)$.

\section{Discussion}

In this study, we assesed the performance of GAS in predicting long-term outcome in elective AAA patients who had undergone EVAR. The long term mortality rate in patients with GAS > 77.5, was almost twice that of the patients with GAS $<77.5$. In addition, every 10 point increase in GAS score resulted in 
almost a two fold increase in risk of long-term mortality. Finally, the five year survival rate in patients with GAS $>77.5$ was significantly less than in those with GAS scores $<77.5$.

There are various risk scoring systems used in the prediction of mortality in patients undergoing repair for AAA. Despite the development of a few new scoring systems within the last decade, GAS still preserves its value in predicting the outcomes following EVAR. Our results also show that GAS has predictive value during long-term follow-up in patients undergoing EVAR for AAA. A systematic review of 608 studies revealed that the most frequently used scoring systems for elective AAA repair were GAS, POSSUM and VBHOM. However, GAS was found to be the most used and validated scoring system for open repair. ${ }^{8}$ Moreover, Nesi et al. [9]. published an article in 2004, in which they compared four different scoring systems with GAS. They concluded that GAS was the most useful scoring system and the easiest one to apply in order to predict AAA surgical outcome. Previous studies conducted in our centre also support the use of GAS in patients undergoing elective and ruptured AAA surgery $[10,11]$.

Nevertheless, Visser et al. modified GAS by adding the type of procedure perfomed and evaluated predicted 30-day mortality in patients with ruptured AAAs treated with EVAR versus surgical AAA repair [12]. Similarly, Choke et al. developed an in-house risk prediction model, in order to predict perioperative mortality following elective AAA repair. They believed that the new models had better performance in predicting perioperative mortality for elective open surgery and EVAR [2].

Most significantly, there are only a few studies in the literature on whether or not GAS predicts long-term survival following EVAR $[5,6]$. The mean survival rates in our study were $90.6 \%$ for the 1 st year, and $70.0 \%$ for the 5th year. Similarly, the overall 1 and 5 -year survival rates were $91.7 \%$ and $76.7 \%$ according to the EUROSTAR registry, which is one of the few studies with results regarding the long-term follow-up after EVAR [5]. Moreover, in the current study, the five year survival rate in patients with GAS $>77.5$ was significantly less than in those with GAS scores $<77.5$. Likewise, the EUROSTAR registry revealed a 5-year overall survival rate of $65.2 \%$ in patients with GAS above the cut-off value of $>83.6$ [5]. These results indicate that the survival rate decreases as the GAS values exceed the cut-off values. Furthermore, the EUROSTAR registry defined the 30-day mortality rate as $6.4 \%$ and $1.6 \%$ in patients with a score above and below the cut-off value respectively [5]. However, long-term mortality rates were not presented in their study. In the present study, the long term mortality rate in patients with GAS $>77.5$, was almost twice that of the patients with GAS $<77.5$. Besides, every 10 point increase in GAS score resulted in almost a 2 fold increase in risk of long-term mortality.

The DREAM trial is the only randomized study comparing AAA patients treated with open repair and EVAR. In this study, Baas et al. concluded that the GAS can be used to predict 30-day and 2-year mortality for both treatment modalities [6]. There was no correlation between the GAS values and in-hospital mortality in both the DREAM study and our study. This is most likely due to the low number of early mortalities. In addition, the DREAM trial supports the idea that GAS was superior in predicting 30-day and 2-year mortality in patients treated with EVAR compared to OR [6]. Their cut-off value for GAS for EVAR, during 2 year follow-up was also the same as ours at $77.5 \%$.

Page 10/16 
According to the results of our study, there were no female long-term mortalities. In contrast, the study by Tümer et al. revealed no difference in all-cause mortality between the genders during the long-term followup period following EVAR [13]. We believe that the abscence of female patients in the long term mortality group of our study may have been due to the comparatively lower number of study participants compared to previous multi-center studies.

The American Association of Anestesiologists (ASA) Physical Status Classification System is one of the grading methods applied in order to categorize the preoperative status as well as to assess postoperative morbidity and mortality $[14,15]$. Another finding of our study was the higher ratio of ASA 3 and 4 patients in the long term mortality group. According to a study published in 2019, ICU and hospital stay were longer in ASA 3 and 4 patients. However, 1 year mortality and morbidity rates did not differ significantly between low and high risk ASA groups [16]. In contrast, our results showed that long-term mortality rates were higher in the high risk ASA 3 and 4 groups and in addition, the duration of ICU stay was weakly correlated with the ASA grades.

Despite a strong correlation found between the GAS and the duration of post-EVAR hospital stay, the mean post procedural hospital stay was not statistically significant in patients with GAS $<77.5$ and $>$ 77.5. The most important reason for this was that ten of the patients who underwent EVAR with a GAS < 77.5 , had an unexpectedly high hospital stay: four due to renal, 3 due to cardiac and 3 due to periperal arterial complications.

Another interesting finding of our study was that the presence of malignancy resulted in a 5 fold increase in risk for long-term mortality. A long-term outcome study of AAA patients, by Ahn et al. documented that mortality was significantly higher in patients with a history of malignancy [17]. The rate of malignancy was four times higher in the long-term mortality group compared to the survivors group in the current study. However, the cause of death was primarily cardiovascular diseases followed by aneurysm related causes in the late-term mortality group. Malignancy was the third common cause of mortality; out of 7 cancer patients in the long-term mortality group, 4 died. The presence of CHF was 9 times higher and CAD was 1.5 times higher in the long-term mortality group compared to the survivors group, which explains why cardiovascular etiologies were the leading cause of death in this study.

The results of our study support that GAS continues to be of value in the prediction of AAA outcome. The easy applicability of the GAS enables its use during long-term follow-up and may help in the education and counselling of patient peri-operatively regarding the long-term risks of EVAR.

\section{Limitations}

The specificity rate for the cut-off value for GAS may seem to be low and less predictive than expected. However, we believe that a specificity of $64 \%$ is a good value for predicting the mortality risk in the longterm follow-up. 


\section{Conclusion}

ROC analysis of the elective AAA patients undergoing EVAR, revealed a GAS cut-off value of 77.5. The presence of malignancy resulted in a 5 fold increase in risk for long-term mortality. Every 1 point increase in GAS score resulted in a 1.06 fold increase in risk of late mortality and every 10 point increase in GAS score resulted in almost a 2 fold increase in risk of long-term mortality. Moreover, the mortality rates in patients above the GAS cut off value almost double compared to those below. Five year survival rates were $14 \%$ higher in those with GAS below the cut off value when compared to those above.

\section{Declarations}

\section{Ethics approval and consent to participate}

This study was approved by ethics committee of Ankara City Hospital.

\section{Authors' contributions}

AÖ: Data gathering, Writing article, Data analysis, submission, project management. MY, GY: Data gathering, Data analysis, MS writing, MS edition. IC: Data gathering. MA, FÇ: Data gathering. EUÜ, HZi: Idea, Writing article, Data analysis. All authors read and approved the final manuscript.

\section{Funding}

The author(s) received no financial support for the research, authorship, and/or publication of this article.

\section{Informed consent}

All participants were informed and filled the written consent.

\section{Consent for publication}

We authors of this study submit our manuscript to BMC cardiovascular disease and consent to use of the data in our article by the journal.

\section{Availability of data and materials}

The datasets used and/or analysed during the current study are available from the corresponding author on reasonable request.

\section{Competing interests}

We authors declare that all of us have no competing interest.

\section{ORCID iDs}


Anıl Özen https://orcid.org/0000-0002-4334-7974

Metin Yılmaz https://orcid.org/0000-0003-2878-2676

Görkem Yiğit https://orcid.org/0000-0002-9500-720X

Ertekin Utku Ünal https://orcid.org/0000-0002-1144-8906

Hakkı Zafer İşcan https://orcid.org/0000-0002-0749-5152

\section{References}

1. Drury D, Michaels JA, Jones L, Ayiku L. Systematic review of recent evidence for the safety and efficacy of elective endovascular repair in the management of infrarenal abdominal aortic aneurysm. Br J Surg. 2005 Aug;92(8):937 - 46. doi: 10.1002/bjs.5123. PMID: 16034817.

2. Choke E, Lee K, McCarthy M, Nasim A, Naylor AR, Bown M, Sayers R. Risk models for mortality following elective open and endovascular abdominal aortic aneurysm repair: a single institution experience. Eur J Vasc Endovasc Surg. 2012 Dec;44(6):549 - 54. doi: 10.1016/j.ejvs.2012.08.011. Epub 2012 Sep 11. PMID: 22981409.

3. Nesi F, Leo E, Biancari F, Bartolucci R, Rainio P, Satta J, Rabitti G, Juvonen T. Preoperative risk stratification in patients undergoing elective infrarenal aortic aneurysm surgery: evaluation of five risk scoring methods. Eur J Vasc Endovasc Surg. 2004 Jul;28(1):52 - 8. doi:

10.1016/j.ejvs.2004.02.010. PMID: 15177232.

4. Samy AK, Murray G, MacBain G. Glasgow aneurysm score. Cardiovasc Surg 1994;2:41-4.

5. Biancari F, Hobo R, Juvonen T. Glasgow Aneurysm Score predicts survival after endovascular stenting of abdominal aortic aneurysm in patients from the EUROSTAR registry. Br J Surg. 2006 Feb;93(2):191-4. doi: 10.1002/bjs.5262. PMID: 16392108.

6. Baas AF, Janssen KJ, Prinssen M, Buskens E, Blankensteijn JD. The Glasgow Aneurysm Score as a tool to predict 30-day and 2-year mortality in the patients from the Dutch Randomized Endovascular Aneurysm Management trial. J Vasc Surg. 2008 Feb;47(2):277 - 81. doi: 10.1016/j.jvs.2007.10.018. PMID: 18241749.

7. İşcan HZ, Ünal EU, Sarıcaoğlu MC, Aytekin B, Soran Türkcan B, Akkaya B, et al. Elektif infrarenal abdominal aort anevrizmasına son beş yıldaki klinik yaklaşımımız: Erken dönem sonuçlar. Damar Cer Derg 2018;27(1):1-7.

8. Patterson BO, Holt PJ, Hinchliffe R, Loftus IM, Thompson MM. Predicting risk in elective abdominal aortic aneurysm repair: a systematic review of current evidence. Eur J Vasc Endovasc Surg. 2008 Dec;36(6):637-45. doi: 10.1016/j.ejvs.2008.08.016. Epub 2008 Oct 14. PMID: 18922709.

9. Nesi F, Leo E, Biancari F, Bartolucci R, Rainio P, Satta J, Rabitti G, Juvonen T. Preoperative risk stratification in patients undergoing elective infrarenal aortic aneurysm surgery: evaluation of five 
risk scoring methods. Eur J Vasc Endovasc Surg. 2004 Jul;28(1):52 - 8. doi: 10.1016/j.ejvs.2004.02.010. PMID: 15177232.

10. Ozen A, Unal EU, Kubat E, Turkcan BS, Caliskan A, Aytekin B, Aksoyek A, Birincioglu CL, Pac M. Glasgow aneurysm scores in patients undergoing open surgical procedure for aortic aneurysm. Vascular. 2015 Jun;23(3):277-80. doi: 10.1177/1708538114548263. Epub 2014 Sep 2. PMID: 25183698.

11. Özen A, Unal EU, Mola S, Erkengel I, Kiris E, Aksöyek A, Saritas A, Birincioğlu CL. Glasgow aneurysm score in predicting outcome after ruptured abdominal aortic aneurysm. Vascular. 2015 Apr;23(2):120-3. doi: 10.1177/1708538114533539. Epub 2014 May 19. PMID: 24841850.

12. Visser JJ, Williams M, Kievit J, Bosch JL; 4-A Study Group. Prediction of 30-day mortality after endovascular repair or open surgery in patients with ruptured abdominal aortic aneurysms. J Vasc Surg. 2009 May;49(5):1093-9. doi: 10.1016/j.jvs.2008.12.027. PMID: 19394540.

13. Tumer NB, Askin G, Akkaya BB, Civelek I, Unal EU, Iscan HZ. Outcomes after EVAR in females are similar to males. BMC Cardiovasc Disord. 2021 Jun 15;21(1):301. doi: 10.1186/s12872-021-02114-2. PMID: 34130661; PMCID: PMC8207773.

14. Wolters $U$, Wolf $T$, Stützer $H$, Schröder T. ASA classification and perioperative variables as predictors of postoperative outcome. Br J Anaesth. 1996 Aug;77(2):217 - 22. doi: 10.1093/bja/77.2.217. PMID: 8881629.

15. Irlbeck T, Zwißler B, Bauer A. ASA classification: Transition in the course of time and depiction in the literature. Anaesthesist 2017;66:5-10.

16. Aytekin B, Akkaya BB, Yılmaz M, Çetinkaya F, Salman N, Ünal EU, et al. Applicability of ASA classification system in elective endovascular aneurysm repair. Turk J Vasc Surg 2019;28(2):101106

17. Ahn S, Min JY, Kim HG, Mo H, Min SK, Min S, Ha J, Min KB. Outcomes after aortic aneurysm repair in patients with history of cancer: a nationwide dataset analysis. BMC Surg. 2020 May 1;20(1):85. doi: 10.1186/s12893-020-00754-3. PMID: 32357930; PMCID: PMC7195758.

\section{Figures}




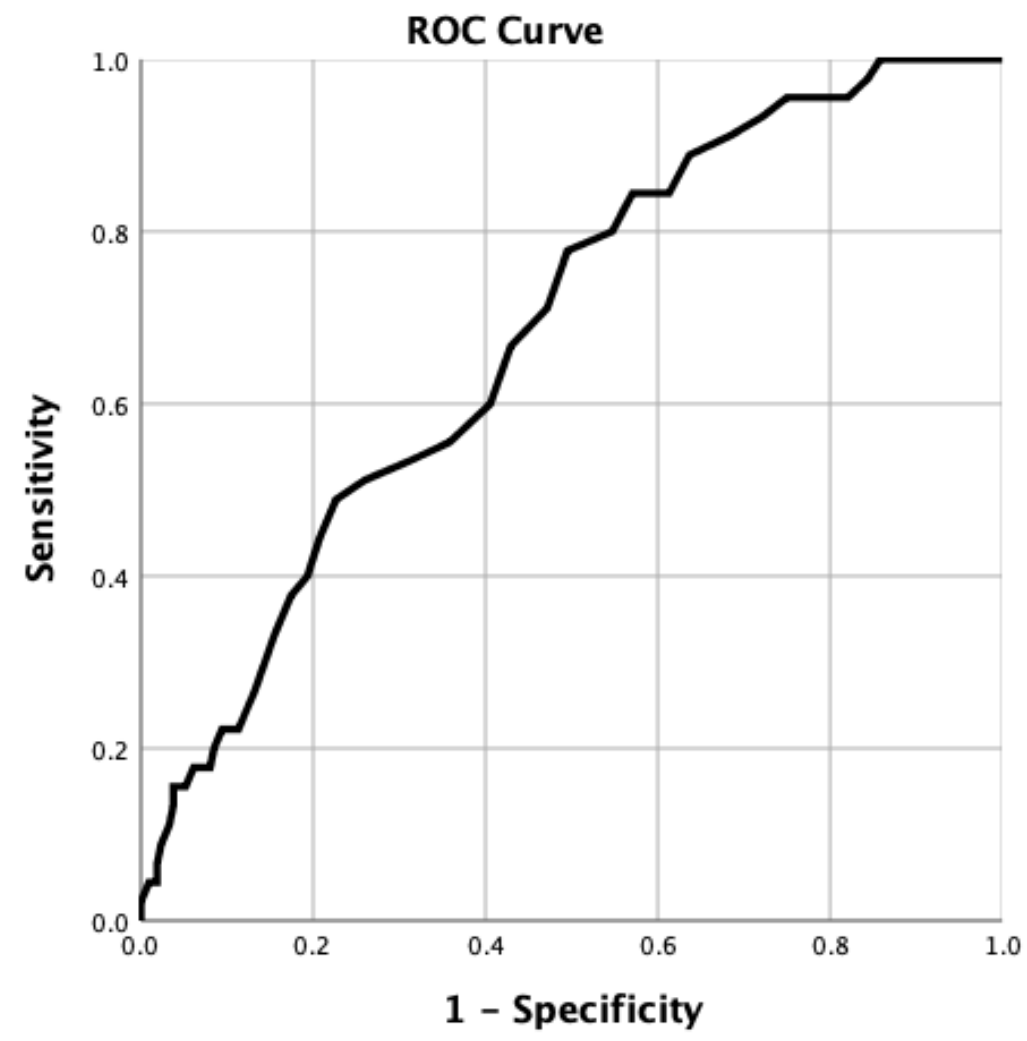

Diagonal segments are produced by ties.

\section{Figure 1}

ROC-curve analysis showing the roc-curve formed at different threshold values

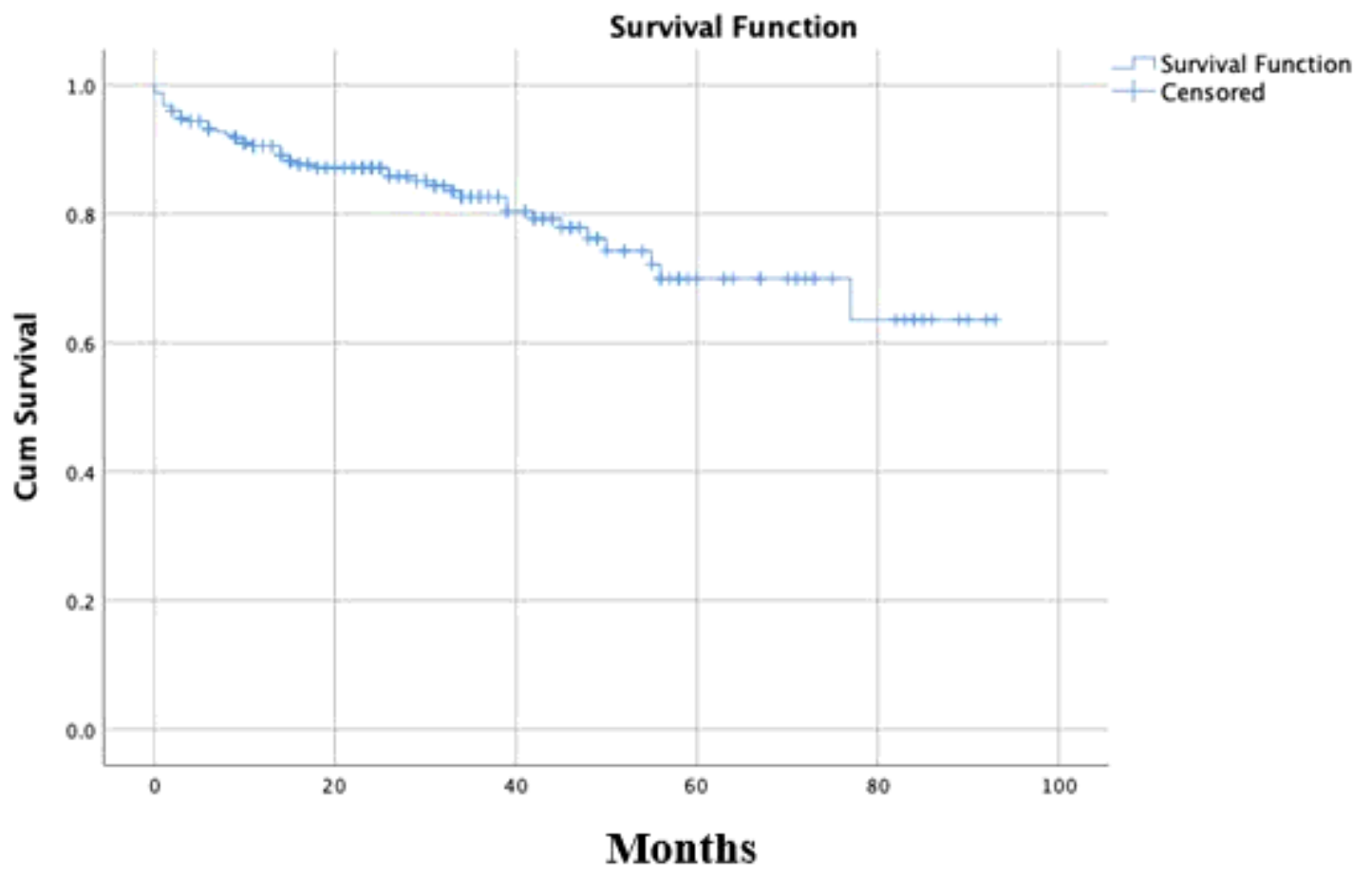

Figure 2 
Survival analysis for the study population

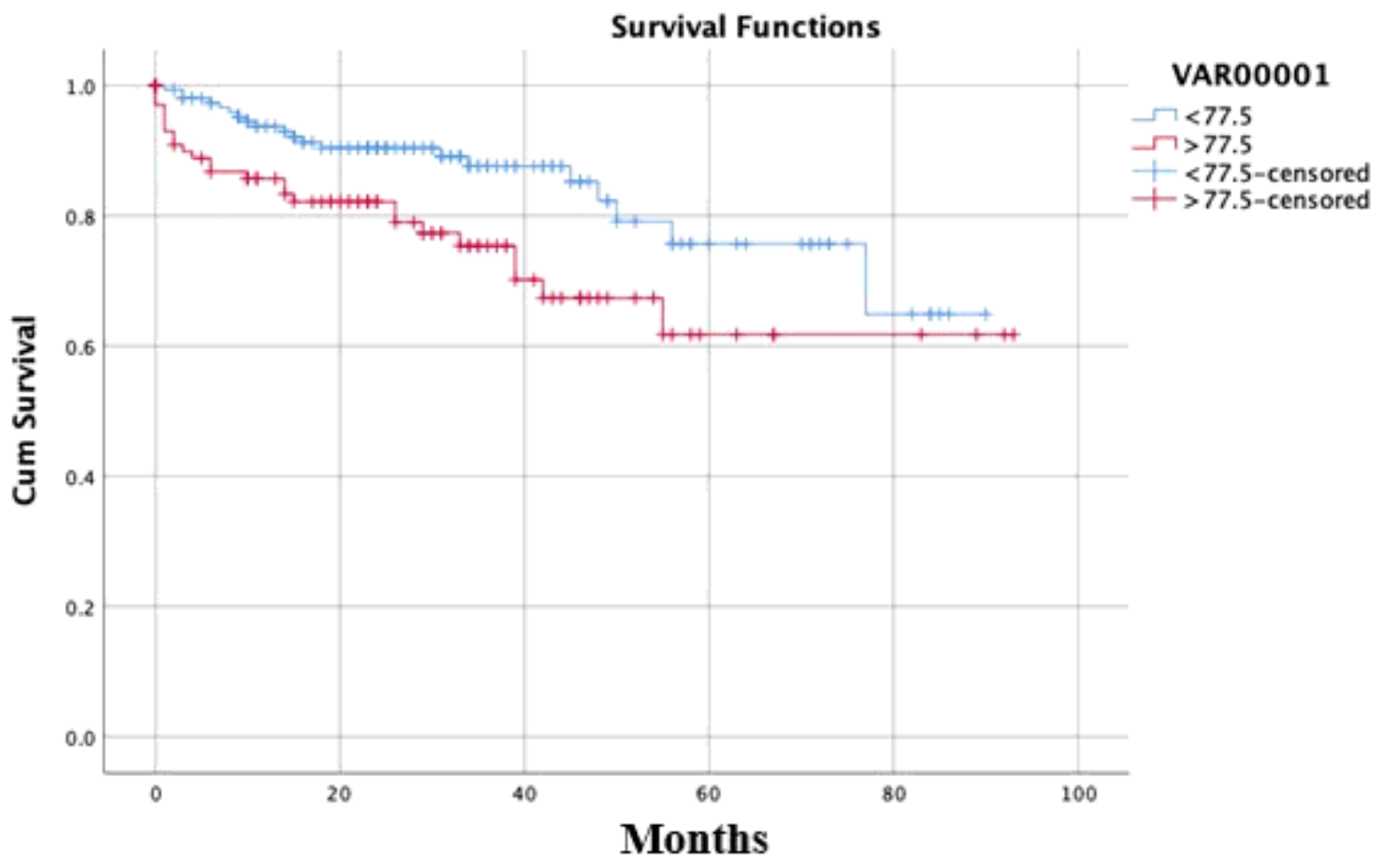

Figure 3

Kaplan-Meier analysis comparing survival rates in patients with GAS $<77.5$ and $>77.5$ 